\title{
PENGARUH KUALITAS PRODUK, PROMOSI, DAN CITRA MEREK TERHADAP KEPUTUSAN PEMBELIAN KOPI MEREK MOOLA PEDAWA
}

\author{
V. Ervina1, M. A. Meitriana² \\ Jurusan Ekonomi dan Akuntansi, Universitas Pendidikan Ganesha, Singaraja \\ E-mail : vikaervina98@gmail.com, ary.meitriana@yahoo.co.id
}

\begin{abstract}
Abstrak
Tujuan penelitian ini untuk mengetahui pengaruh kualitas produk, promosi dan citra merek terhadap keputusan pembelian Kopi Merek Moola Pedawa. Jenis penelitian ini ialah asosiatif dengan pendekatan kuantitatif. Populasinya yakni konsumen yang pernah membeli dan mengkonsumsi Kopi Merek Moola Pedawa sebanyak 384 responden, didapat dengan teknik purposive sampling. Metode pengumpulan data menggunakan kuesioner. Teknik analisis data menggunakan regresi linear berganda. Pengujian hipotesis pun menggunakan uji $t$, dan uji $F$. Hasil penelitian menunjukkan bahwa secara parsial maupun simultan kualitas produk, promosi, dan citra merek berpengaruh positif terhadap keputusan pembelian
\end{abstract}

Kata kunci: Kualitas Produk, Promosi, Citra Merek, Keputusan Pembelian

\begin{abstract}
The purpose of this study was to discover the effect of product quality, promotion and brand image on the purchase decision of Moola Pedawa Coffee. This type of research is associative with a quantitative approach. The population was customers who have bought and consumed Moola Pedawa Coffee for 384 respondents, collected by the purposive sampling technique. The data collection method was using questionnaires. The data analysis technique was using multiple linear regression. Hypothesis tests were conducted using the $t$ test and $f$ test. The results showed that partially and simultaneously product quality, promotion, and brand image have a positively effect on purchase decisions
\end{abstract}

Keywords : Brand Image, Product Quality, Promotion, Purchase Decision

\section{Pendahuluan}

Keputusan pembelian merupakan tindakan konsumen sebelum melakukan pembelian dengan mencari informasi hingga membandingkan produk dengan merek lainnya (Sutisna, 2001). Keputusan pembelian penting untuk diperhatikan, agar pelaku usaha dapat menciptakan strategi pemasaran untuk menarik minat beli konsumen. Saat membeli suatu produk, konsumen memiliki banyak alasan mengapa mereka membeli produk tersebut seperti karena harga, pelayanan, dan manfaat dari produk sehingga mereka merasa puas membeli produk tersebut. Tetapi ada juga konsumen yang melakukan pembelian dengan alasan kebutuhan akan suatu produk (Kotler and Keller, 2016).

Assael (2005) mengemukakan faktor yang mempengaruhi keputusan pembelian yakni faktor individu konsumen, faktor lingkungan, dan faktor strategi pemasaran. Dalam hal persangian usaha, banyak konsumen yang tertarik dan menyukai produk dengan alasan strategi pemasaran yang dilakukan pelaku usaha. Hal ini dikarenakan setiap produk akan dikenal oleh konsumen jika pelaku usaha melakukan strategi pemasaran yang tepat misalnya dengan menghasilkan produk yang berkualitas (Assael, 2005). Oleh sebab itu, agar kepercayaan konsumen tidak hilang terhadap produk yang dibeli, produsen harus selalu memproduksi produk sesuai dengan standar yang ditetapkan (Kotler and Amstrong, 2016).

Selain menjaga kualitas produk, bentuk strategi pemasaran lainnya yang umum dilakukan pelaku usaha yakni promosi (Assael, 2005). Menurut Lupiyoadi (2013) promosi yakni sarana komunikasi pemasar dengan konsumen. Adanya promosi, bisa memudahkan pelaku usaha untuk memperkenalkan produk yang dihasilkan sehingga dapat meningkatkan penjualan produk sedangkan bagi konsumen promosi digunakan untuk memperoleh informasi sebanyaknya mengenai produk yang akan dibelinnya (Sunyoto, 2012). 
Namun sebenarnya konsumen membeli produk tidak hanya melihat strategi pemasaran pelaku usaha. Tetapi konsumen memutusan membeli produk berdasarkan alasan dan pendapat mereka sendiri seperti halnya sikap konsumen terhadap citra merek produk tersebut (Assael, 2005). Lebih lanjut Setiadi (2003) menjelaskan bahwa citra merek ialah segala sesuatu yang dipikirkan dan dirasakan ketika konsumen mengetahui merek tertentu. Kesan yang baik pada merek produk memiliki kemungkinan yang lebih besar mengambil perhatian konsumen untuk melakukan pembelian dan perusahaan bisa membangun citra yang baik pada mereknya (Firmansyah, 2019).

Bali merupakan salah satu daerah penghasil kopi terbaik. Hasil kopi banyak dimanfaatkan oleh para pelaku usaha untuk dikembangkan menjadi usaha industri. Kopi merupakan minuman legendaris yang banyak diminati oleh masyarakat dan jumlah permintaan kopi yang cukup tinggi membuat semakin banyaknya usaha industri kopi yang bermunculan. Permintaan akan produk kopi ini dipengaruhi oleh selera konsumen dan presepsi konsumen terhadap produk tersebut. Dengan demikian, pelaku usaha dituntut untuk menciptakan produk dengan kualitas yang baik serta menerapkan strategi pemasaran agar mampu bersaing dan unggul dibanding kopi merek lainnya. Dari fenomena persaingan ketat antar usaha industri kopi ini, banyak dimanfaatkan oleh para pelaku indutri kopi untuk mendapatkan keuntungan.

Kopi Moola Pedawa adalah salah satu merek kopi yang mengalami persaingan ketat antar usaha industri.Usaha industri Kopi Moola Pedawa berlokasi di Desa Pedawa, Kecamatan Banjar, Kabupaten Buleleng. Usaha industri ini sudah berdiri sejak tahun 1975 yang merupakan usaha turun menurun tetapi dapat mempertahankan keberadaannya ditengah persaingan yang ketat dan dapat tetap menjaga kesetiaan konsumen untuk membeli produk yang dihasilkan hingga saat ini.

Kualitas produk Kopi Moola Pedawa tidak kalah baik dari produk kopi lainnya. karena pemiliki usaha Kopi Moola Pedawa ini selalu mengutamakan kualitas bahan baku yang digunakan demi kepuasan para konsumennya. Kopi Moola Pedawa selalu menjaga kualitas produknya dengan mempertahankan cita rasa dan aroma yang khas pada kopi sehingga membuat kesan positif pada konsumen setelah mengkonsumsi produk kopi ini. Dengan menjaga standar kualitas tersebut diharapkan konsumen tidak akan membeli produk kopi lainnya.

Dari hasil observasi yang telah dilakukan, para konsumen memutuskan membeli produk Kopi Moola Pedawa tidak hanya karena kualitas dan citra merek pada produk kopi ini melainkan juga dengan alasan informasi yang mereka peroleh mengenai produk Kopi Moola Pedawa melalui sosial media. Sosial media pun dijadikan wadah promosi bagi pemilik usaha Kopi Moola Pedawa untuk memperkenalkan produk kopinya pada masyarakat luas. Adapun kegiatan promosi yang dilakukan seperti aktif mengikuti pameran serta bekerja sama dengan pusat pertokoan oleh-oleh untuk memasarkan dan memperkenalkan produk kopinya ke masyarakat luas, serta memanfaatkan media sosial dimana dalam sosial media tersebut disajikan informasi mengenai produk kopi, suasana kedai kopi, hingga video pembuatan produk Kopi Moola Pedawa. Sehingga konsumen pun menjadi tertarik dan berminat untuk membeli produk Kopi Moola Pedawa.

Penelitian ini menggunakan teori dari Assael (2005) dimana keputusan pembelian dipengaruhi oleh faktor individu konsumen seperti sikap terhadap citra merek dan strategi pemasaran yang dilakukan pihak produsen seperti kualitas produk, dan kegiatan promosi. Maka judul yang diambil yakni "pengaruh kualitas produk, promosi dan citra merek terhadap keputusan pembelian Kopi Merek Moola Pedawa"

\section{Metode}

Jenis penelitian ialah asosiatif dengan pendekatan kuantitatif. Pelaksanaan penelitian dilakukan dilokasi usaha industri Kopi Moola Pedawa di Desa Pedawa, Kecamatan Banjar, Kabupaten Buleleng dengan jarak 27 KM sebelah barat dari pusat kota Singaraja. Populasinya adalah konsumen yang pernah membeli dan mengkonsumsi produk Kopi Moola Pedawa. Penentuan sampel menggunakan purposive sampling. Teknik penentuan sampel 
dilakukan dengan menggunakan rumus Lemeshow karena jumlah populasi tidak terhingga (Riduwan and Akdon, 2010). Sehingga jumlah sampel yang didapat sebanyak 384 responden.

Penelitian menggunakan data primer dalam bentuk kuesioner dan observasi. Dimana dalam kuesioner berisikan skala likert. Sebelum kuesinoner disebar, kuesioner harus diuji tingkat valid dan reliable. Kuesioner dikatakan valid jika sig $<0,05$. Sedangkan bisa dikatakan reliabel jika Cronbach's Alpha $>0,60$. Adapun teknik analisis yaitu regresi linier berganda. Sebelum menganalisis dilakukan pengujian (1) uji normalitas, (2) uji linearitas, (3) uji multikolinieritas Untuk pengujian hipotesis menggunakan uji $t$ dan uji $f$. Dimana penerimaan atau penolakan hipotesis jika sig $<0,05$ maka Ho ditolak, dan jika sig $>0,05$ maka Ho diterima (Ghozali, 2011).

\section{Hasil dan Pembahasan}

Persamaan regresi linear berganda disajikan sebagai berikut.

Tabel 1

Regresi Linear Berganda

\begin{tabular}{|c|c|c|c|c|c|}
\hline \multirow[b]{2}{*}{ Model } & \multicolumn{2}{|c|}{$\begin{array}{l}\text { Unstandardized } \\
\text { Coefficients }\end{array}$} & \multirow{2}{*}{$\begin{array}{l}\text { Standardized } \\
\text { Coefficients } \\
\text { Beta }\end{array}$} & \multirow[b]{2}{*}{$\mathrm{T}$} & \multirow[b]{2}{*}{ Sig. } \\
\hline & $\mathrm{B}$ & Std. Error & & & \\
\hline 1 (Constant) & 31.152 & 3.347 & & 9.308 & .000 \\
\hline Kualitas Produk & .156 & .039 & .210 & 4.033 & .000 \\
\hline Promosi & .228 & .073 & .162 & 3.123 & .002 \\
\hline Citra Merek & .172 & .072 & .126 & 2.384 & .018 \\
\hline
\end{tabular}

Sumber : Output SPSS 16.0 for Wndows

Persamaan regresi disajikan sebagai berikut.

$$
\begin{aligned}
& Y=a+\beta 1 X 1+\beta 2 X 2+\beta 3 X 3+\varepsilon \\
& Y=31.152+0,156 X 1-0,228 X 2+0,172 X 3
\end{aligned}
$$

Berdasarkan persamaan tersebut, diperoleh nilai konstanta sebesar 31.152 maka variabel independen bernilai konstan atau nol. Variabel dependen memiliki nilai positif sebesar 31.152. Selanjutnya, variabel kualitas produk (X1) memiliki nilai positif 0,156 , variabel promosi (X2) memiliki nilai positif 0,228 , dan variabel citra merek (X3) memiliki nilai positif 0,172 . Dengan nilai koefisien regresi yang positif maka $\mathrm{X} 1, \mathrm{X} 2$, dan $\mathrm{X} 3$ berpengaruh positif terhadap $\mathrm{Y}$.

\section{Pengaruh Kualitas Produk Terhadap Keputusan Pembelian}

Uji t disajikan sebagai berikut.

Tabel 2

\begin{tabular}{|c|c|c|c|c|c|c|}
\hline \multirow{2}{*}{\multicolumn{2}{|c|}{ Model }} & \multicolumn{2}{|c|}{$\begin{array}{l}\text { Unstandardized } \\
\text { Coefficients }\end{array}$} & \multirow{2}{*}{$\begin{array}{c}\text { Standardized } \\
\text { Coefficients } \\
\text { Beta }\end{array}$} & \multirow[b]{2}{*}{$\mathrm{T}$} & \multirow[b]{2}{*}{ Sig. } \\
\hline & & $\mathrm{B}$ & Std. Error & & & \\
\hline \multirow[t]{2}{*}{1} & (Constant) & 31.152 & 3.347 & & 9.308 & .000 \\
\hline & $\begin{array}{l}\text { Kualitas } \\
\text { Produk }\end{array}$ & .156 & .039 & .201 & 4.033 & .000 \\
\hline
\end{tabular}

Uji t Kualitas Produk Terhadap Keputusan Pembelian

Sumber : Output SPSS 16.0 for Wndows 
Berdasarkan tabel 2 menunjukan nilai signifikasi $0,000<0,05$, maka Ho ditolak, artinya ada pengaruh.

\section{Pengaruh Promosi Terhadap Keputusan Pembelian}

Uji t disajikan sebagai berikut.

Tabel 3

Uji t Promosi Terhadap Keputusan Pembelian

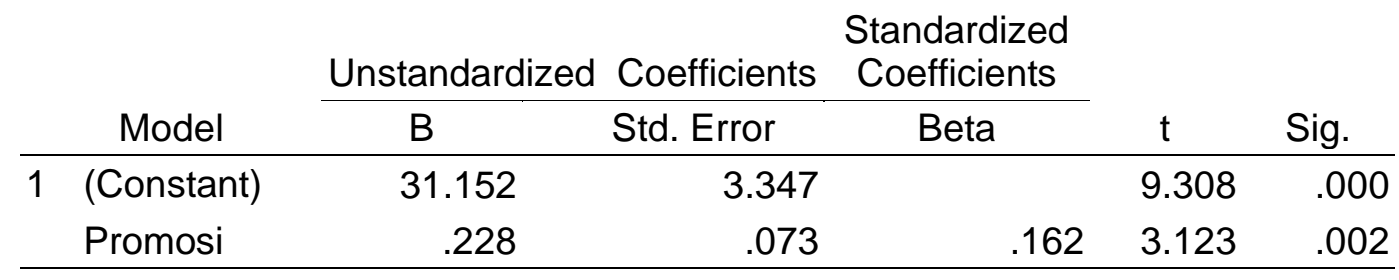

Sumber: Output SPSS 16.0 for Wndows

Berdasarkan tabel 3 menunjukan nilai signifikasi 0,002 <0,05. Maka Ho ditolak, artinya ada pengaruh.

\section{Pengaruh Citra Merek Terhadap Keputusan Pembelian}

Uji t disajikan sebagai berikut.

Tabel 4

Uji t Citra Merek Terhadap Keputusan Pembelian

\begin{tabular}{|c|c|c|c|c|c|c|}
\hline \multirow{2}{*}{\multicolumn{2}{|c|}{ Model }} & \multicolumn{2}{|c|}{$\begin{array}{l}\text { Unstandardized } \\
\text { Coefficients }\end{array}$} & \multirow{2}{*}{$\begin{array}{c}\begin{array}{c}\text { Standardized } \\
\text { Coefficients }\end{array} \\
\text { Beta }\end{array}$} & \multirow[b]{2}{*}{$\mathrm{T}$} & \multirow[b]{2}{*}{ Sig. } \\
\hline & & $\mathrm{B}$ & Std. Error & & & \\
\hline \multirow[t]{2}{*}{1} & (Constant) & 31.152 & 3.347 & & 9.308 & .000 \\
\hline & Citra Merek & .172 & .072 & .126 & 2.384 & .018 \\
\hline
\end{tabular}

Sumber : Output SPSS 16.0 for Wndows

Berdasarkan tabel 4 menunjukan nilai signifikasi 0,018 <0,05. Maka Ho ditolak, artinya ada pengaruh.

Pengaruh Kualitas Produk, Promosi, dan Citra Merek Terhadap Keputusan Pembelian Uji f disajikan sebagai berikut.

Tabel 5

Uji F Kualitas Produk, Promosi, dan Citra Merek terhadap Keputusan Pembelian

\begin{tabular}{llrrrrr} 
Model & & Sum of & & & & \\
\multicolumn{1}{l}{ Squares } & Df & Mean Square & F & Sig. \\
\hline 1 & Regression & 297.759 & 3 & 99.253 & 20.687 & $.000^{\mathrm{a}}$ \\
& Residual & 1823.200 & 380 & 4.798 & & \\
& Total & 2120.958 & 383 & & & \\
\hline
\end{tabular}

Sumber : Output SPSS 16.0 for Wndows 
Berdasarkan tabel 5 menunjukan nilai signifikasi $0,000<0,05$. Maka Ho ditolak, artinya ada pengaruh.

Kualitas produk berpengaruh terhadap keputusan pembelian Kopi Merek Moola Pedawa. Diperkuat pendapat Hermawan (2012) bahwa kualitas yang baik pada produk berpengaruh besar terhadap pilihan dan keputusan konsumen dalam membeli produk, jadi dengan produk berkualitas konsumen lebih percaya dan tertarik melakukan pembelian. Hasil ini didukung penelitian Saputra, dkk (2017) menunjukkan bahwa kualitas produk berpengaruh terhadap keputusan pembelian.

Promosi berpengaruh terhadap keputusan pembelian Kopi Merek Moola Pedawa. Hasil penelitian ini didukung oleh teori Assael (2005) menyatakan bahwa konsumen akan membeli barang dipengaruhi oleh strategi pemasaran promosi yang dilakukan oleh pelaku bisnis. Hasil ini membuktikan bahwa promosi sangat membantu para pemasar dalam memperkenalkan produknya dan bisa mempengaruhi konsumen. Promosi yang tepat pun dapat meningkatkan minat konsumen dalam membeli suatu produk (Tjiptono, 2016). Hasil ini didukung penelitian Edwar (2015) menunjukkan bahwa promosi berpengaruh terhadap keputusan pembelian.

Citra merek berpengaruh terhadap keputusan pembelian Kopi Merek Moola Pedawa. Citra merek Kopi Moola Pedawa berhasil menyakinkan konsumen mengenai produknya hingga konsumen memutuskan membeli produknya. Teori itu didukung pendapat Assael (2005) menyatakan bahwa konsumen dalam membeli barang dipengaruhi oleh dirinya sendiri seperti sikap dalam menilai citra merek produk. Alfian (2012) citra merek yang positif, membuat banyak orang mempercayai merek tersebut dan memutuskan untuk membelinya. Hasil ini didukung penelitian Foster (2016) menunjukkan bahwa citra merek berpengaruh terhadap keputusan pembelian.

Kualitas produk, promosi, dan citra merek berpengaruh terhadap keputusan pembelian Kopi Merek Moola Pedawa. Hasil ini didukung oleh teori Assael (2005) menyatakan bahwa keputusan pembelian konsumen dipengaruhi oleh strategi pemasaran berupa kualitas produk dan promosi yang dikendalikan oleh pemasar. Dari sisi konsumen, konsumen membeli produk dipengaruhi oleh dirinya sendiri seperti sikap dalam menilai citra merek produk.

\section{Simpulan dan Saran}

Dari pembahasan sebelumnya, disimpulkan bahwa terdapat pengaruh antara kualitas produk, promosi, dan citra merek terhadap keputusan pembelian baik secara parsial maupun simultan.

Berdasarkan simpulan, yang dapat peneliti sarankan yaitu perlunya pemilik usaha untuk lebih aktif dalam memperkenalkan produknya kepada konsumen misal dengan membuat iklan produk Kopi Moola Pedawa, tujuannya agar semakin banyaknya konsumen yang membeli produk kopi ini. Pemilik usaha dapat memanfaatkan marketplace, website atau blog, dan pemasangan poster sebagai media pembuatan iklan. Bagi peneliti berikutnya, diharapkan lebih mengembangkan faktor lain sehingga dapat menambah wawasan mengenai keputusan pembelian konsumen.

\section{Daftar Pustaka}

Assael, H. 2005. Consumer Behavior and Marketing Action. New York: Thomson Learning.

Edwar. 2015. Pengaruh Promosi Penjualan terhadap Keputusan Pembelian Komputer Merek Acer di CV Era Komputer. Skripsi tidak diterbitkan. Palembang: Universitas IBA.

Firmansyah, A. 2019. Pemasaran Produk dan Merek (Planning \& Strategy). Surabaya: CV Penerbit Qiara Media.

Foster, B. 2016. Impact of Brand Image on Purchasing Decision on Mineral Water Product "Amidis" (Case Study on Bintang Trading Company). American Research Journal of Humanities and Social Sciences, 2(1), pp. 1-11. 
Ghozali, I. 2011. Aplikasi Analisis Multivariate Dengan Program SPSS. Semarang: Badan Penerbit Universitas Diponegoro.

Hermawan, A. 2012. Komunikasi Pemasaran. Jakarta: Erlangga.

Kotler, P. \& Amstrong, G. 2016. Prinsip-Prinsip Pemasaran. Jakarta: Erlangga.

Kotler, P. \& Keller, K. L. 2016. Manajemen Pemasaran. Jakarta: PT Indeks.

Lupiyoadi, R. 2013. Manajemen Pemasaran Jasa berbasis Kompetensi. Jakarta: Salemba Empat.

Riduwan \& Akdon. 2010. Rumus dan Data dalam Analisis Data Statistika. Bandung: Alfabeta.

Saputra, S. T., Hidayat, K. \& Sunarti. 2017. Pengaruh Kualitas Produk terhadap Keputusan Pembelian dan Dampaknya terhadap Kepuasan Konsumen Pengguna Iphone (Survei pada Mahasiswa Fakultas IImu Administrasi Universitas Brawijaya Malang). Jurnal Administrasi Bisnis, Vol. 50, No.6, Hal. 86 - 89.

Setiadi, N. J. 2003. Perilaku Konsumen Perspektif Kontemporer pada Motif, Tujuan, dan Kenginan Konsumen. Jakarta: Prenada Media Group.

Sunyoto, D. 2012 Dasar - Dasar Manajemen Pemasaran Konsep, Strategi, dan Kasus. Yogyakarta: CAPS (Center for Academic Publishing Service).

Tjiptono, F. 2016. Service, Quality, dan Satisfaction. Yogyakarta: Andi Offset. 